\title{
Thank you to our Referees from 2015
}

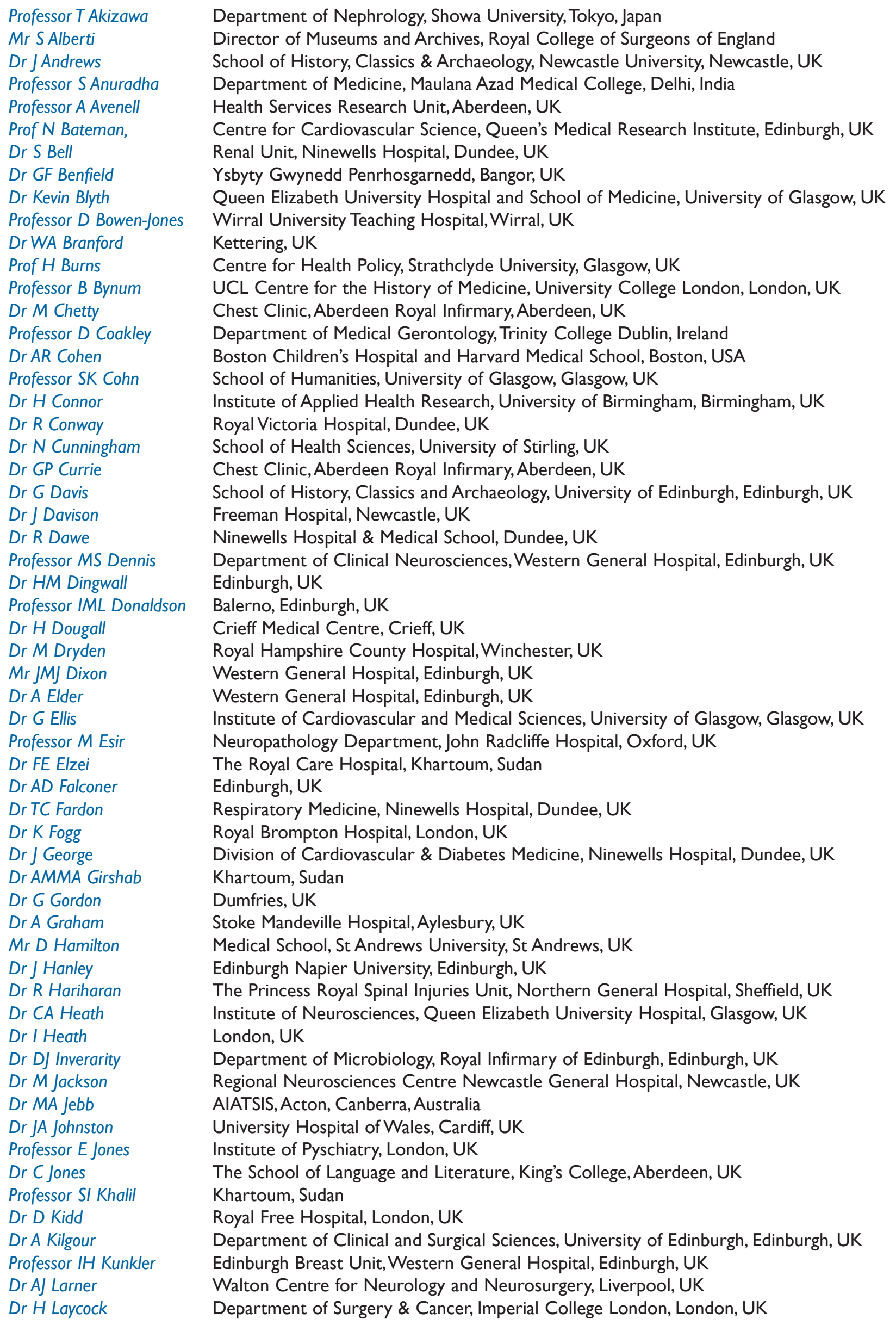


Dr JP Leach

Professor A Lees

Dr JL Lordan

Dr RJ MacFadyen

Mr R MacFarlane

Mr IMC Macintyre

Dr E Malcolm

Dr P Mark

Dr RM McGowan

Dr D McKee

Dr D McKeon

DrT Millard

Mr I Milne

Dr M Moore

Dr B Moore McCann

Dr E Morrison

Dr P Newey

Professor M Nicolson

Dr A Noman

Mr JE Norman

Dr M O'Kane

DrAS Oo

Dr J Palace

Dr M Park

Ms C Parry

Professor TJ Peters

DrW Pietkiewicz

DrT Quinn

Professor E Reynolds

Dr N Reynolds

Professor A Rusnock

Dr C Schofield

Dr E Shepherd

Mr C Sherlaw-Johnson

Dr. PM Short

Dr G Sissons

Dr I Smith

Dr RL Soiza

Professor JM Starr

Professor D St Clair

Dr J Stone

Professor AD Struthers

Dr P Syme

Dr B Szwejkowski

Dr R A Tarala

Dr HThomas

Dr B Thompson

Professor A Vale

Professor CVaughan

Dr Dr S Verma

Dr NVickers

Professor NVincent

Professor M Walters

Ms M-F Weiner

Dr A Wilkinson

Dr P Wilkinson

Dr D P Wilks

Dr DJ Wright
Institute of Neurological Sciences, Queen Elizabeth University Hospital, Glasgow, UK Institute of Neurology, University College London, London, UK

Freeman Hospital, Newcastle, UK

Ballarat Base Hospital, Ballarat, Victoria, Australia

Wellcome Library, Wellcome Trust, London, UK

Edinburgh, UK

School of Medicine, Ninewells Hospital, Dundee, UK

Institute of Cardiovascular and Medical Sciences, University of Glasgow, Glasgow, UK

West of Scotland Regional Genetics Service, Glasgow, UK

Greater Manchester Centre for Clinical Neurosciences, Hope Hospital, Salford, UK

School of Medical Sciences, Bangor University, Gwynedd, Wales, UK

Gloucestershire Royal Hospital, Gloucester, UK

Royal College of Physicians of Edinburgh, Edinburgh, UK

Centre for Medical History, University of Exeter, Exeter, UK

Trinity College Dublin, Dublin, Ireland

Queen Elizabeth University Hospital, Glasgow, UK

Division of Cardiovascular \& Diabetes Medicine, Ninewells Hospital, Dundee, UK

Centre for the History of Medicine, University of Glasgow, Glasgow, UK

Cardiology Department, Aberdeen Royal Infirmary, Aberdeen, UK

Strathfield, Australia

Altnagelvin Area Hospital, Londonderry, Northern Ireland

Pyinn Oo Lwin Hospital, Myanmar

Department of Clinical Neurology, John Radcliffe Hospital, Oxford, UK

Centre for Open Studies, University of Glasgow, Glasgow, UK

Royal College of Physicians and Surgeons of Glasgow, Glasgow, UK

London, UK

The Walton Centre, Liverpool, UK

Institute of Cardiovascular and Medical Sciences, Glasgow Royal Infirmary, Glasgow, UK

King's College, London, UK

Ninewells Hospital and Medical School, Dundee, UK

Department of History, University of Rhode Island, Kingston, RI, USA

Ninewells Hospital and Medical School, Dundee, UK

Freeman Hospital, Newcastle, UK

Nuffield Trust, London, UK

Ninewells Hospital and Medical School, Dundee

Noble's Hospital, Isle of Man, UK

Gartnavel Royal Hospital, Glasgow, UK

Aberdeen Royal Infirmary, Aberdeen, UK

Royal Victoria Hospital, Edinburgh, UK

Institute of Medical Sciences, Aberdeen, UK

Department of Clinical Neurosciences, Western General Hospital, Edinburgh, UK

Department of Clinical Pharmacology \& Therapeutics, Ninewells Hospital, Dundee, UK

Borders General Hospital, Melrose, UK

Ninewells Hospital and Medical School, Dundee, UK

Department of Respiratory Medicine, Royal Perth Hospital, Perth, Australia

Wansbeck General Hospital, Northumberland, UK

School of Medical Education, Newcastle University, Newcastle, UK

National Poisons Information Service, City Hospital, Birmingham, UK

Mercy University Hospital, Cork, Ireland

Brighton \& Sussex Medical School, University of Sussex, Brighton, UK

Department of English, King's College, London, UK

School of History, University of East Anglia, Norwich, UK

Institute of Cardiovascular and Medical Sciences, Western Infirmary, Glasgow, UK

Princes Risborough, Buckinghamshire, UK

Royal Victoria Hospital, Dundee, UK

Royal Victoria Infirmary, Newcastle, UK

Regional Infectious Diseases Unit, Western General Hospital, Edinburgh, UK

Liverpool Heart and Chest Hospital NHS, Foundation Trust, Liverpool, UK 